\title{
PENGARUH KUALITAS PRODUK DAN KUALITAS LAYANAN TERHADAP KEPUASAN PELANGGAN PADA RUMAH MAKAN PADANG TALAGO BIRU PADASUKA
}

\author{
Siti Nurjanah $^{1}$, Rina Sukmawati ${ }^{2}$, Muslima $^{3}$, Subhi Alwi ${ }^{4}$ \\ ${ }^{1}$ Institut Agama Islam Negeri (IAIN) METRO \\ ${ }^{2}$ Universitas Negeri Yogyakarta \\ ${ }^{3}$ Universitas Islam Lamongan \\ ${ }^{4}$ Universitas Sangga Buana YPKP
}

\begin{abstract}
ABSTRAK
This study aims to explain the effect of product quality and service quality on customer satisfaction at Talago Biru Padasuka Restaurant where the independent variables, namely product quality and service quality, on customer satisfaction as the dependent variable. The research was conducted in Padasuka Village, Cimenyan District, Bandung City, West Java. Data collection methods used are interviews and questionnaires filled out by respondents, namely customers of the blue talagoPadasuka restaurant. Sampling of 100 respondents, in this study using convenience sampling technique. The research method of this thesis is quantitative method, the analysis used includes validity test, reliability test, multiple linear regression analysis, and hypothesis testing which includes $F$ test and $T$ test. correlation coefficient, coefficient of determination. The results showed that with a significance of $0.000<0.10$ then there was a significant effect between product quality and service quality on customer satisfaction.
\end{abstract}

Keywords: Product Quality, Service Quality, Customer Satisfaction

\begin{abstract}
ABSTRAK
Penelitian ini bertujuan untuk menjelaskan Pengaruh Kualitas Produk Dan Kualitas Layanan Terhadap Kepuasan Pelanggan di Rumah Makan Talago Biru Padasuka dimana variabel independen yaitu kualitas produk dan kualitas layanan, terhadap kepuasan pelanggan sebagai variabel dependen-nya. Penelitian dilakukan di desa padasuka, kecamatan Cimenyan, Kota Bandung, Jawa Barat. Metode pengumpulan data yang digunakan adalah dengan wawancara dan kuesioner/angket yang diisi oleh responden yaitu pelanggan rumah makan talago biru padasuka. Pengambilan sampel sebanyak 100 responden, dalam penelitian ini menggunakan teknik convenience sampling. Metode penelitian ini adalah metode kuantitatif, analisis yang digunakan meliputi uji validitas, uji reabilitas, analisis regresi linier berganda dan pengujian hipotesis yang meliputi uji $\mathrm{F}$ dan uji T. koefisien korelasi, koefisien determinasi. Hasil penelitian menunjukan bahwa dengan signifikansisebesar $0.000<0.10$ maka ada pengaruh signifikan antara kualitas produk dan kualitas layanan terhadap kepuasan pelanggan.
\end{abstract}

Kata Kunci: Kualitas Produk, Kualitas Layanan, Kepuasan Pelanggan. 


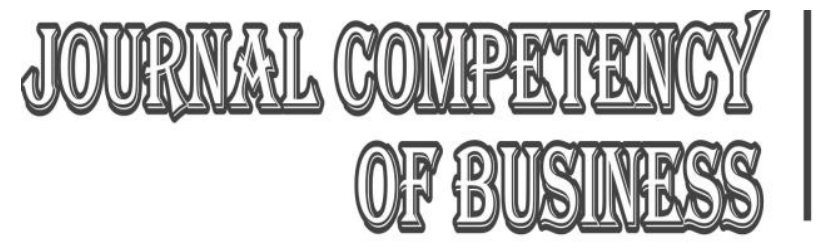

Fakultas Ekonomi, Universitas Cokroaminoto Yogyakarta

\section{PENDAHULUAN}

Era saat ini, persaingan bisnis di pada suka semakin ketat. Hal ini menuntut setiap perusahaan untuk dapat memaksimalkan kinerja perusahaannya agar mampu bersaing di pasar. Perusahaan harus mampu memahami kebutuhan dan keinginan konsumennya. Oleh karena itu, perusahaan harus merancang strategi pemasaran yang kuat agar dapat menciptakan kepuasan bagi konsumennya dan dapat bertahan dalam persaingan bisnis.

Salah satu bisnis yang berkembang pesat dan merasakan ketatnya persaingan saat ini adalah bisnis dalam bidang makanan atau dikenal dengan istilah kuliner. Persaingan yang semakin ketat tersebut di tandai dengan banyak nya bisnis di bidang kuliner yang menghasilkan produk dengan jenis yang sama akan tetapi produk dan pelayanan beranekaragam. Dengan demikian, Rumah Makan Talago Biru dituntut untuk menciptakan strategi yang dapat menarik para konsumen untuk mengonsumsi produk yang ditawarkan agar mampu bersaing dan unggul disbanding pesaingnya. Rumah makan Talago Biru harus selalu melakukan perubahan atau inovasi dan memberikan pelayanan yang terbaik kepada konsumen agar konsumen merasa puas terhadap produk yang mereka beli.

Semakin maraknya bisnis kuliner yang terjadi di Pada suka terdapat beranekaragam bisnis kuliner di Padasuka sehingga persaingan dalam menjalankan usaha semakin ketat. Berbagai ragam kuliner yang ada di padasuka dan semakin berkembangnya jumlah gerai yang menyajikan kuliner di padasuka, hal ini menjadikan daya tarik penulis untuk melakukan penelitian tentang bisnis kuliner yang difokuskan pada salah satu jenis kuliner yaitu masakan padang talago biru padasuka. Rumah makan talago biru padasuka berdiri sejak tahun 2014 merupakan salah satu usaha yang dimiliki oleh Rudi hartono yang bergerak dibidang kuliner.

\section{TINJAUAN PUSTAKA}

\section{Kualitas Produk}

Pengertian kualitas produk memiliki inti pada upaya pemenuhan kebutuhan dan keinginan pelanggan yang bertujuan untuk mengimbangi harapan pelanggan. Menurut Kotler dan Amstrong (2014: 11) kualitas produk adalah kemampuan dalam sebuah produk 
Fakultas Ekonomi, Universitas Cokroaminoto Yogyakarta

dalam memperagakan fungsinya, hal ini termasuk keseluruhan durabilitas, realibititas, ketepatan, kemudahan pengoperasian, dan reparasi produk, juga atribut produk lainnya. Sedangkan menurut Kotler dan Keller (2016: 164) kualitas produk adalah kemampuan suatu barang untuk memberikan hasil atau kinerja yang sesuai bahkan melebihi apa yang diinginkan pelanggan.

\section{Jenis - JenisProduk}

Menurut indriyono Gitosudarmo (2017:120) jenis - jenis produk dibagi menjadi dua macam yaitu:

1. Produk yang berwujud (Tangible Product)

Produk yang berwujud biasanya disebut "barang" atau "goods", barang yang berwujud dibagi menjadi dua macam, yaitu:

a) Barang konsumsi (CobsumerGoos), merupakan barang yang dibeli oleh konsumen untuk memenuhi kebutuhannya dan akan dikonsumsinya sendiri, seperti, barang kebutuhan pokok, kebutuhan pelengkap atau alat - alat pelengkap hidup, dan barang kebutuhan kemewahan atau barang special.

b) Barang industri (industrial Goods), merupakan barang yang dibeli oleh konsumen untuk menjalankan industry atau usaha bisnisnya dan bukan untuk dikonsumsinya sendiri.

2. Produk Yang Tak Berwujud (intangible product)

Produk yang tak berwujud sering disebut "jasa" atau "service" jasa ini banyak sekali jenisnya karena masyarakat juga memiliki kebutuhan jasa yang beranekaragam. Produk jasa ini bisa berupa jasa pendidikan, kecantikan, kebugaran, dan lain sebagainya.

\section{Dimensi Kualitas Produk}

Menurut Sangadji dan Sopiah dalam Sudaryono (2016: 86) dimensi kualitas produk terbagi menjadi tiga yaitu:

1. Kinerja (Performance)

2. Kehandalan (Reliabilitas)

3. Estetika (Aestethic) 


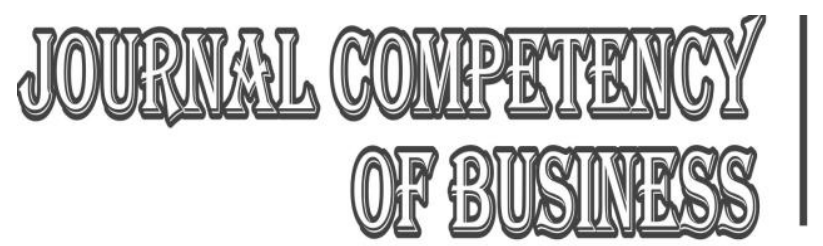

Fakultas Ekonomi, Universitas Cokroaminoto Yogyakarta

\section{Tingkat Produk}

Perusahaan harus mengetahui berapa tingkatan produk ketika akan menambah produknya. Menurut Kotler dan Keller (2016: 390) produk memiliki lima tingkatan, diantaranya:

1. Manfaat Inti Layanan atau manfaat yang benar-benar dibeli pelanggan.

2. Produk Dasar Pemasar harus mengubah manfaat inti menjadi produk dasar.

3. Produk yang diharapkan serangkaian atribut dan kondisi yang biasanya diharapkan pembeli saat mereka beli produk ini.

4. Produk augmented pemasar menyiapkan produk tambahan yang melebihi pelanggan harapan.

5. Produk potensial yang mencakup semua kemungkinan augmentasi dan transformasi produk atau penawaran mungkin akan terjadi dimasa mendatang.

\section{Kualitas Layanan}

Menurut Nasution yang dikutip oleh Mhd Rusydi (2017: 39) kualitas pelayanan adalah tingkat keunggulan (excellence) yang diharapkan dan pengendalian atas keunggulan tersebut untuk memenuhi keinginan para pelanggan.

Menurut Parasuraman dalam Tjiptono (2016: 157) terdapat faktor yang mempengaruhi sebuah layanan adalah expected service (layanan yang diterima). Jika layanan yang diterima sesuai bahkan dapat memenuhi apa yang diharapkan maka jasa dikatakan baik atau positif. Jika perceived service melebihi expected service, maka kualitas pelayanan dipersepsikan sebagai kualitas ideal. Sebaliknya apabila perceived service lebih jelek dibandingkan expected service, maka kualitas pelayanan dipersepsikan negative atau buruk. Oleh sebab itu baik tidaknya kualitas pelayanan tergantung pada kemampuan perusahaan dan sifatnya memenuhi harapan pelanggan secara konsisten.

\section{Dimensi Kualitas Layanan}

Menurut Tjiptono (dalam, buku Darmawanto 2015) dimensi kualitas layanan terbagi menjadi empat yaitu:

1. Bukti fisik

2. Reabilitas

3. Daya tangkap 
Fakultas Ekonomi, Universitas Cokroaminoto Yogyakarta

4. Kesopanan

\section{KepuasanPelanggan}

Kepuasan pelanggan adalah tingkat perasaan konsumen setelah membandingkan antara apa yang diterima dan harapannya Umar (2015: 65), seorang konsumen jika merasa puas dengan nilai yang diberikan oleh produk atau jasa, sangat besar kemungkinannya menjadi pelanggan dalam waktu yang lama.

Menurut Lovelock dan Wirtz yang dikutip oleh Fandy Tjiptono (2016: 74) kepuasan adalah suatu sikap yang diputuskan berdasarkan pengalaman yang didapatkan. Sangat dibutuhkan penelitian untuk membuktikan ada atau tidaknya harapan sebelumnya yang merupakan bagian terpenting dalam kepuasan.

\section{Jenis - Jenis Kepuasan Pelanggan}

Menurut Almana (2018: 37), ada empat jenis kepuasan pelanggan diantaranya yaitu:

1. Tanpa Kepuasan

2. Kepuasan yang lemah

3. Kepuasan tersembunyi

4. Kepuasan premium

\section{Tahap - Tahap Kepuasan}

Menurut Sangadji (2018: 33) ada tiga tahapan kepuasan pelanggan diantaranya yaitu:

1. The Courtship

2. The Relationship

3. The Merriage

\section{KeuntunganKepuasan Pelanggan}

Menurut Sangadji (2018: 33), terdapat enam metode keuntungan kepuasan pelanggan diantaranya yaitu:

1. Dapa tmengurangi biaya pemasaran (karena menarik biaya yang baru itu lebih mahal)

2. Dapat mengurangi biaya setiap transaksi

3. Dapat mengurangi biaya turn over pelanggan (karena pergantian dari pelanggan yang lebih sedikit)

4. Dapat meningkatkan penjualan silang, yang akan menghasilkan pangsa pasar 
Fakultas Ekonomi, Universitas Cokroaminoto Yogyakarta perusahaan

5. Mendorong word of mouth yang lebih positif, dengan terjadinya asumsi bahwa semua pelanggan yang loyal berarti mereka pelanggan yang merasa puas

6. Dapat mengurangi dari biaya kegagalan.

\section{Karakteristik Kepuasan Pelanggan}

Menurut Griffin dalam Hurriyati (2015: 130), karakteristik kepuasan pelanggan diantaranya sebagai berikut:

1. Melakukan setiap pembelian secara teratur(makes regular repeat purchases)

2. Membeli diluar lini produk /jasa(purchases across product and service lines)

3. Merekomendasikan produk - produk lain (refars other)

4. Menunjukan dari kekebalan daya tarik produk sejenis dari pesaing(demonstrates immunity to the full of the competition).

\section{Dimensi Kepuasan Pelanggan}

Menurut Donni junipriansa (2017: 210) ada tiga dimensi kepuasan pelanggan diantaranya, yaitu:

1. Harapan (Expectation)

2. Kinerja (Performance)

3. Pengalaman (Experience)

\section{Hubungan antara kualitas produk dan kualitas layanan terhadap kepuasan pelanggan}

Salah satu strategi untuk mencapai kepuasan pelanggan di prioritaskan pada Faktor kualitas produk dan kualitas layanan untuk menentukan kepuasan pelanggan. Kualitas produk dan kualitas layanan merupakan unsure penting dalam strategi pemasaran kualitas produk yang baik dan kualitas layanan yang mumpuni serta mampu memenuhi kepbutuhan dan keinginan pelanggan maka dapat di harapkan meningkatkan kepuasan pelanggan yang tentu nantinya akan meningkatkan penjualan produk.

Kualitas produk dan kualitas layanan sangat berhubungan dengan kepuasan pelanggan. Kualitas produk dan kualitas layanan merupakan satu hal yang penting berpengaruh terhadap kepuasan pelanggan. Kualitas produk akan menjadi salah satu pilihan pelanggan untuk menggunakan produk tersebut, semakin kuatnya kualitas produk 
Fakultas Ekonomi, Universitas Cokroaminoto Yogyakarta

maka akan memberikan kepuasan bagi pelanggan dalam mengkonsumsi produk dan jika kualitas produk yang diberikan sesuai dengan harapan konsumen, maka akan memberikan kepuasan bagi pelanggan.halini juga di dukung oleh penelitian yang dilakukan oleh (Muslima, 2020) tentang pengaruh kualitas produk dan kualitas pelayanan terhadap kepuasan pelanggan pada percetakan penakarya kota bima. Yang menunjukan bahwa kualitas produk dan kualitas layanan merupakan faktor penting dalam mempengaruhi kepuasan pelanggan.

Hal ini menunjukan adanya tingkat keeratan hubungan antara kualitas produk dan kualitas layanan terhadap kepuasan pelanggan yang mempunyai pengaruh berkesinambungan.

\section{Hipotesis Penelitian}

Model hipotesis yang di gunakan dalam penelitian ini dapat dilihat pada gambar.1

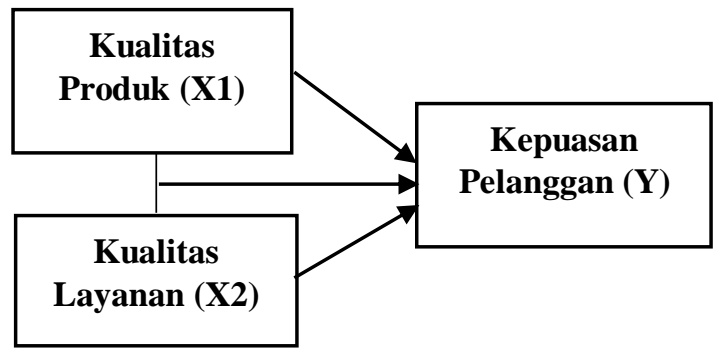

\section{Gambar. 1 Model Hipotesis}

Hipotesis penelitian ini adalah sebagai berikut:

$\mathrm{H}_{1}$ : Kualitas produk, kualitas layanan, berpengaruh significan terhadap kepuasan pelanggan di Rumah MakanTalago Biru Padasuka

$\mathrm{H}_{2}$ : Kualitas produk berpengaruh signifikan terhadap kepuasan pelanggan di Rumah Makan Talago Biru Padasuka.

$\mathrm{H}_{3}$ : Kualitas layanan berpengaruh signifikan terhadap kepuasan pelanggan di Rumah Makan Talago Biru Padasuka.

\section{METODE PENELITIAN}

Metode yang digunakan dalam penelitian

Ini adalah metode deskriptif dan metode verifikatif. Dalam penelitian ini yang menjadi objek penelitian adalah Pengaruh Kualitas Produk Dan Kualitas Pelayanan Terhadap Kepuasan Pelanggan yang beralokasi di Desa Padasuka, Kecamatan Cimeunyan, Kota 
Bandung.Sampel yang diambil dalam penelitian ini sebanyak 100 orang responden yang merupakan pelanggan RM Talago Biru Pada suka. Teknik sampling yang digunakan adalah purposive sampling. Data dikumpulkan dengan menggunakan kuesioner yang kemudian di analisis dengan analisis deskriptif dan verifikatif.

Hasil uji validitas dan reabilitas menunjukan bahwa data yang di peroleh adalah valid dan reliabel., sehingga data yang diperoleh dalam penelitian ini adalah layak untuk di uji. Nilai koefisien korelasi tertinggi pada masing - masih item untuk variabel kualitas produk (X1) sebesar 0,620 berada diantara 0.60 - 0.799, artinya variabel kualitas produk menunjukan hubungan yang kuat dan positif terhadap variabel kepuasan pelanggan. Sedangkan nilai koefisien korelasi pearson untuk variabel kualitas layanan sebesar 0.722 berada diantara $0.60-0.799$, artinya variabel kualitas layanan menunjukan hubungan yang kuat dan positif terhadap kualitas pelanggan. Reabilitas di ketahui pada variabel $\mathrm{X}_{1}=0.623$; $\mathrm{X}_{2}=0.798 ; \mathrm{Y}=0.724$; semua hasil uji reabilitas menunjukan angka lebih $>0,6$ sehingga dinyatakan reliable (Sugiyono, 2017: 199).

\section{HASIL PENELITIAN DAN PEMBAHASAN}

Berdasarkan penyebaran kuesioner terhadap 100 orang responden (pelanggan) berdasarkan jenis kelamin, usia, Pendidikan terakhir, pekerjaan, jumlah penghasilan perbulan, pelanggan yang membeli nasi padang di rumah makan talago biru padasuka.

Responden berdasarkan jenis kelamin laki - laki sebesar 39\% dan perempuan 61\%, artinya sampel populasi pelanggan mayoritas adalah perempuan. Responden berdasarkan usia responden terbesar adalah memiliki pekerjaan pegawai swasta dengan jumlah presentase $47 \%$, untuk pelajar/mahasiswa dengan jumlah presentase $20 \%$, pekerja sebagai wiraswasta dengan jumlah presentase 9\%, dan untuk ibu rumah tangga dengan besar presentase $17 \%$. Dengan demikian dapat diketahui mayoritas responden berdasarkan pekerjaan adalah pegawai swasta sebesar 47\%. Responden berdasarkan pendapatan per/bulan Sebagian besar penghasilan Rp2.600.000 - Rp5.000.000/ bulan berjumlah 55\% dari total sampel penelitian, kemudian untuk sisanya berpenghasilan dari Rp1.000.000 - Rp2.500.000/ bulan yang berjumlah $7 \%$, penghasilan $<\mathrm{Rp} 1.000 .000 /$ bulan berjumlah $20 \%$, dan penghasilan Rp5.000.000 - Rp10.000.000/ bulan berjumlah 18\%. Dengan demikian mayoritas pelanggan utama berdasarkan pendapatan perbulan Rp2.600.000 - Rp5.000.000/bulan. 


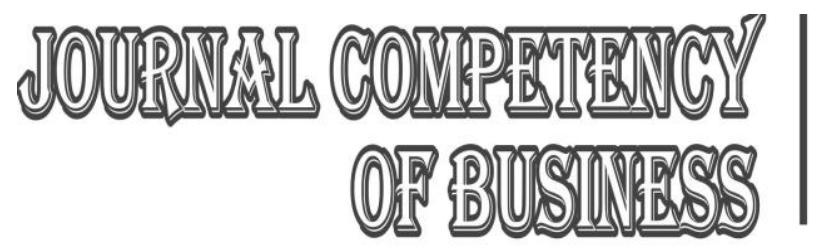

Fakultas Ekonomi, Universitas Cokroaminoto Yogyakarta

\section{Hasil Analisis Jalur (Path Analysis)}

Hasil analisis jalur pada penelitian inidapat dilihat pada Tabel 1.

Tabel 1 Hasil Uji Regresi Linier Berganda

\begin{tabular}{|c|c|c|c|c|c|}
\hline \multicolumn{6}{|c|}{ Coefficients $^{a}$} \\
\hline \multirow[b]{2}{*}{ Model } & \multicolumn{2}{|c|}{$\begin{array}{c}\text { Unstandardiz } \\
\text { ed } \\
\text { Coefficients }\end{array}$} & \multirow{2}{*}{ 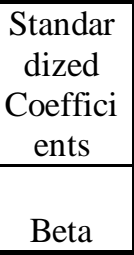 } & \multirow[b]{2}{*}{$\mathrm{t}$} & \multirow[b]{2}{*}{ Sig. } \\
\hline & B & $\begin{array}{l}\text { Std. } \\
\text { Error }\end{array}$ & & & \\
\hline $1 \quad$ (Constant) & 4.963 & .983 & & 5.048 & .000 \\
\hline $\begin{array}{l}\text { Kualitas } \\
\text { Produk }\end{array}$ & .196 & .096 & .204 & 2.036 & .044 \\
\hline $\begin{array}{l}\text { Kualitas } \\
\text { Layanan }\end{array}$ & .361 & .063 & .574 & 5.733 & .000 \\
\hline
\end{tabular}

Sumber: hasil pengolahan SPSS

$$
\mathrm{Y}=4,963+0,196 \mathrm{X} 1+0,361 \mathrm{X} 2+\mathrm{e}
$$

Persamaan diatas dapat diartikan sebagai berikut:

$\alpha=4,963 \quad$ Konstanta $(\alpha)$, maka kepuasan pelanggan bernilai sebesar 4,963

$\mathrm{X}_{1}=0,196$ Merupakan nilai koefisien regresi variabel Kualitas Produk (X1) terhadap variabel Kepuasan Pelanggan (Y) artinya jika Kualitas Produk (X1) meningkat sebesar satu satuan dan variabel lainnya konstan, maka variabel Y akan meningkat 0,196. Koefisien bernilai positif artinya antara Kualitas Produk (X1) terhadap Kepuasan Pelanggan (Y) berhubungan positif. Kenaikan Kualitas Produk (X1) akan mengakibatkan kenaikan pada Kepuasan Pelanggan (Y).

$\mathrm{X}_{2}=0,361 \quad$ Merupakan nilai koefisien regresi variabel Kualitas Layanan (X2) terhadap Kepuasan Pelanggan (Y) artinya jika Kualitas Layanan (X2) meningkat sebesar satu satuan dan variabelnya konstan, maka variabel $\mathrm{Y}$ akan meningkat sebesar 0,361. Koefisien bernilai positif artinya antara Kualitas Layanan (X2) terhadap Kepuasan Pelanggan (Y) berhubungan positif. Kenaikan Kualitas Layanan (X2) akan mengakibatkan kenaikan pada Kualitas Pelanggan (Y). 


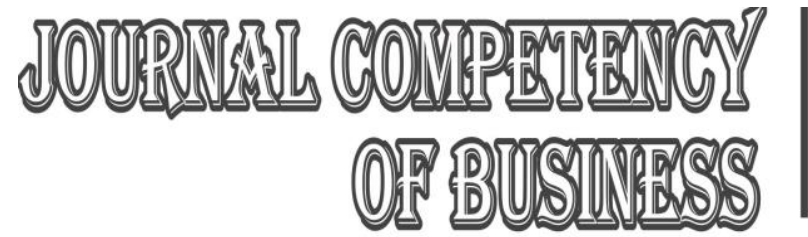

Fakultas Ekonomi, Universitas Cokroaminoto Yogyakarta

Tabel 2

Hasil Uji Koefisien Determinasi

\begin{tabular}{|l|r|r|r|c|}
\hline & & Model Summary & Adjusted R \\
Model & $\mathrm{R}$ & $\begin{array}{c}\text { Std. Error } \\
\text { of the } \\
\text { Estimate }\end{array}$ \\
\hline 1 & $.735^{\mathrm{a}}$ & .540 & .531 & 1.74400 \\
\hline
\end{tabular}

Sumber: pengolahan SPSS

Berdasarkan hasil pengujian koefisien determinasi pada tabel diatas, dipengaruhi nilai koefisien $\mathrm{R}$ square (R2) sebesar 0,540 atau 54,0\% jadi bisa diambil kesimpulan sebesar pengaruh kualitas produk dan kualitas layanan terhadap kepuasan pelanggan sebesar $0,54(54,0 \%)$.

\section{KESIMPULAN DAN SARAN}

\section{Kesimpulan}

1. Kualitas produk berpengaruh signifikan sebesar $19,6 \%$ terhadap kepuasan pelanggan.

2. Kualitas layanan berpengaruh signifikan sebesar $36,1 \%$ terhadap kepuasan pelanggan.

3. Kualitas produk dan kualitas layanan berpengaruh signifikan sebesar $54 \%$ terhadap kepuasan pelanggan.

\section{Saran}

1. Kualitas Produk

a. Berdasarkan gambaran responden mengenai Estetika (Aestethic) menyatakan cukup, akan tetapi rumah makan talago biru padasuka harus terus meningkatkan penampilan produknya agar dapat menaikan selera pelanggan.

b. Berdasarkan gambaran responden mengenai Kehandalan (Reliabilitas) kurang baik, dalam hal tersebut pihak rumah makan talago biru padasuka harus meningkatkan lagi tingkat kemampuan rasa yang dimiliki, dan harus ada varian rasa yang di spesialkan yang tidak dimiliki oleh produk lagi sehingga dapat menambah pelanggan yang berkunjung dan meningkatkan kepuasan pelanggan.

c. Berdasarkan gambaran responden mengenai Kinerja (Performance) kurang baik, dalam hal ini rumah makan talago biru harus menambah lagi produk yang 
Fakultas Ekonomi, Universitas Cokroaminoto Yogyakarta

belum ada pada rumah makan padang umumnya, agar pelanggan tidak merasa kecewa dengan menu yang di sajikan.

2. Kualitas Layanan

Dilihat dari indikator yang masih terdapat nilai dibawah rata rata yaitu pada dimensi kurang aktual dan juga kurang handalnya dalam suatu pelayanan pada saat pelanggan meminta berkunjung kerumah makan talago biru padasuka, terkadang pelayan ketiduran dan suka bermain game di belakang, sehingga layanan yang ada di rumah makan talago biru harus di tingkatkan lagi dan professional dalam bekerja, agar pelanggan tidak kecewa dan meningkatkan nilai kepuasan layanan.

3. Kepuasan Pelanggan

Berdasarkan gambaran responden mengenai kepuasan pelanggan dapat dikatakan kurang baik, hal yang harus dilakukan rumah makan talago biru padasuka harus meningkatkan lagi kualitas produk dan kualitas layanan terutama pada produk yang berkualitas, harus meningkatkan rasa dan aroma yang maksimal serta layanan yang baik, sehingga pelanggan merasa puas dan akan kepuasan terhadap rumah makan talago biru padasuka.

\section{DAFTAR PUSTAKA}

Andi Andika Wirawan, Herman Sjahruddin, Nurlaely Razak. (2019). Pengaruh Kualitas Produk Dan Lokasi Terhadap Loyalitas Pelanggan Melalui Kepuasan Pelanggan Sebagai Variabel Intervening Pada Lamuna Coffee Di Kabupaten Bone. Jurnal Organisasi Dan Manajemen 1 (8). 15 - 26.

Aneke Punuindoong, Harry J Sumampouw, Intan Puspitasari. (2018). Pengaruh Kualitas Produk Dan Kesesuaian Harga Terhadap Peningkatan Penjualan Beras Premium Pada Perum Bulog Divisi Regional Sulawesi Utara Dan Gorontalo. Jurnal Administrasi Bisnis. $69-57$.

Agus Supandi Soegoto. (2018). Pengaruh Kualitas Produk, Harga, Dan Kualitas Pelayanan Terhadap Kepuasan Konsumen Pada PT. Air Manado. Jurnal EMBA, 3(7), 1658 1667.

Afdy Rasyid Ikhprastyo. (2018). Pengaruh Kualitas Pelayanan, Kualitas Produk Dan Promosi Terhadap Loyalitas Pelanggan Melalui Kepuasan Pelanggan Di Mister Geprek Bandar Lampung.

Alfian Rahmat, Suharyono, Swasta Priambada. Pengaruh Customer Relationship Management Terhadap Kepuasan Dan Loyalitas Pelanggan (Survei Pada Pelanggan Service Kendaraan Auto2000 Kediri Suharmadji. Jurnal Administrasi Bisnis 1 
Fakultas Ekonomi, Universitas Cokroaminoto Yogyakarta (nov). $153-160$.

Budi D Soebakir, Bode Lumanauw, Ferdy Roring (2018). Pengaruh Brand Harga Dan Kualitas Pelayanan Terhadap Keputusan Pelanggan Membeli Di Kedai Kopi Gudang Imaji Manado. Jurnal EMBA 4 (Sep). 2843 - 3852.

Daniel Adhi Satria dan Helena Sidharta. (2017). Pengaruh Citra Merek Dan Kualitas Produk Terhadap Minat Beli Konsumen Porkball. Jurnal Manajemen dan Star Up Bisnis, 3 (agustus), 398 - 408.

Daniel Okki Rizki Kesuma Adi, Aziz Fathoni SE MM, Leonardo Budi H SE MM(2018). Pengaruh Kualitas Pelayanan, Harga Dan Promosi Terhadap Keputusan Pembelian Produk CKE Teknik Semarang.

LystiaIstiningtyas dan Lumawati - Lukmawati. (2019). Tracer study of the psychology faculty of UIN Raden Fatah Palembang in 2018: satisfaction of alumni and stakeholders on the implementation of Islamic psychology study programs. Jurnal Konseling dan Pendidikan 19(11). 8 - 15.http://jurnal.konselingindonesia.com

Novianti, Endri, dan Darlius. (2018). Kepuasan Pelanggan Memediasi Pengaruh Kualitas Pelayanan Dan Promosi Terhadap Loyalitas Pelanggan. Jurnal Ilmiah Manajeme 1 (Feb). 90 - 108. http://dx.doi.org/10.22441/mix.2018.v8i1006

Slamet Heri Winarno. (2018). Faktor - Faktor Penentu Pengaruh Kualitas Produk Dan Harga Terhadap Loyalitas Pelanggan Indosat IM3 OOREDOO. Jurnal Ekonomi \& Ekonomi Syariah 2(6). 2559 - 3410.

Sarifudin, Rehendra Maya. (2019). Implementasi Manajemen Pemasaran Jasa Pendidikan Dalam Meningkatkan Kepuasan Pelanggan Di Madrasah Aliyah Terpadu (MAT) Darul Falah Bogor. Jurnal Manajemen Pendidikan Islam 25(7). 135 - 154. http://doi.10.30868/im.v2i02.513

Vina Islami. (2019). Pengaruh Kualitas Pelayanan, Servicescape Dan Harga Terhadap Kepuasan Konsumen. Jurnal Sekretari Dan Manajemen 2(September). 2550 0805. https://doi.org/10.31294/widyacipta.v3il

Wiwit Dian Rahmatika. (2019). Hubungan Kualitas Pelayanan Dengan Kepuasan Pelanggan Pada Salon Widya Di Desa Cokrah Kecamatan Pemalang Kabupaten Pemalang. 